\title{
Extended Reality in the World Wide Web: Investigating and Testing the Use Cases of WebVR Manuals
}

\author{
Roger Seiler \\ Zurich University of Applied Science \\ roger.seiler@zhaw.ch
}

\author{
Daniel Widmer \\ Zurich University of Applied Science \\ daniel.widmer@zhaw.ch
}

\begin{abstract}
Web Virtual Reality (WebVR) extends the World Wide Web $(W W W)$ in its possibilities by enabling it to present $3 D$ objects. Past research suggests that this could enhance accessibility and calls for further research on user acceptance of this technology. This study conducts an online experiment with a manual for folding an origami figure and compares data from a classic approach versus one where a WebVR manual is presented. Time, quality, knowledge transfer, and motivation are measured, and mediation is tested for usability, cognition, imagination, and comprehensibility. Participants show higher levels of motivation, mediated by comprehensibility and less cognitive effort. The reduced cognitive strain enhances knowledge transfer. Furthermore, the time used is lower in the WebVR setting than in the traditional one. This effect is moderated by usability. Regarding quality, no significant effects are reported.
\end{abstract}

\section{Introduction}

Not only is the market around extended realities (XR) such as augmented reality (AR), virtual reality (VR), and mixed reality (MR) growing [1], but VR is used more and more in the context of the WWW with the technology called WebVR. Researchers wonder if WebVR can further fuel the adoption of VR [2] because hardware costs are no longer a main barrier [3]. Furthermore, some researchers reason that WebVR may even enhance accessibility [2] and call for further analysis regarding user acceptance of MR [4]. Additionally, user instruction manuals are quite common, and in the case of IKEA, many people may have their own experiences with reading manuals to assemble a product that comes in parts. But customer support use cases of user instruction manuals or maintenance operations are a field where manuals are often used too.
Therefore, this research paper seeks to shed light on the use case of manuals and test a version implemented with WebVR compared with a traditional manual to answer the research question of how user perception differs in a virtual manual compared with a classic paper manual.

\section{Literature}

In this section, an overview of relevant concepts as well as literature is given, and WebVR is introduced. Extended reality (XR) is the term that can be used to cover $\mathrm{VR}, \mathrm{AR}$, and MR. In this paper, a focus on WebMR and VR is appropriate as the artifact used is a WebVR implementation.

\subsection{Virtual Reality}

According to Milgram, VR is "an environment is one in which the participant observer is totally immersed in, and is able to interact with, a completely synthetic world" [5, p. 1372]. VR can be further subdivided into a technological, a human-computer interaction (HCI) and a mental experience perspective [6]. In line with this categorization is the one of Burdea and Coiffet that base their characterization of VR on the three Is: immersion, interaction, and imagination [7].

Typically, a head-mounted display (HMD) is used (e.g., HP OmniCept, HTC Vive, Oculus, and others), and controllers that can have up to six degrees of freedom. Immersion, interaction, as well as imagination can be implemented with this technology. When wearing an HMD, the user is physically immersed in the virtual world. This interactive, immersive experience tends to be quite intense but can also lead to cybersickness due to conflicting sensory stimulations. Cybersickness will have a negative impact on users' intentions to use VR [8]. 


\subsection{WebXR}

WebXR is the term that encapsulates both VR and AR applications that run without additional hardware or software in a web browser, and users can immerse into virtual worlds through their smartphone, desktop, or HMD [9].

WebVR combines 3D VR representation with web technology, and 3D objects can be seen and interacted without an HMD or six-degree-of-freedom controllers.

A-Frame is a JavaScript framework that is open source [10] and can be used to implement WebVR applications that run in browsers. These applications run in a browser without the need for controllers or additional hardware. Research on multi-user online VR engines based on a peer-to-peer (P2P) network has been conducted [11] and is an example of the technological maturity of the technology.

This technology is platform independent and does not have to be installed. Therefore, a URL request is sufficient to experience WebVR, which is an advantage of this technology. Its disadvantages are its quality limitations, and except for a split-screen mode (e.g., used with smart phone cradles such as Google Cardboard), the view is not stereoscopic, rendering this experience typically less immersive than one with binocular HMDs.

\subsection{Empirical Evidence}

A systematic literature review of AR in maintenance finds evidence that it can be used in the context of consumer technology such as printers and notebooks to conduct basic maintenance tasks [12]. However, although development platforms, hardware, visualization, tracking, and authoring are covered, WebVR is not specifically mentioned or analyzed. Only large-screen solutions are analyzed, as well as error rates and execution time drop when AR is used [13].

Online retail has also discovered AR as a technology. The effects of AR on cognition as well as on consumers' product attitude have been studied, in which cognitive load and cognitive fluence play as mediators [14]. The study uses high and low physical control of the $3 \mathrm{D}$ product as manipulation.

Furthermore, meta-analysis concludes technology such as VR and AR have positive effects on learning [15]-[20] and more specifically on the transfer of knowledge. Even the framework MAGIS (mobile augmented-reality games for instructional support) has been implemented [19].

However, the authors of this paper did not identify specific research on WebVR and instruction manuals even though the research introduced above points toward an application in this area.
Therefore, it seems promising to use this technology in the context of a user manual because here, explicit knowledge is made accessible to users or knowledge may even be transferred. Furthermore, FAQ (frequently asked question) webpages, videos, microsites, or just plain PDF documents are common when supporting customers seeking help. Therefore, this paper contributes to prior research by closing this research gap and exploring the effects of 3D WebVR instruction manuals compared with a conventional user instruction manual.

\subsubsection{Sense of Presence}

Empirical evidence suggests that an immersive sense of presence has positive effects on learning outcomes and presence and performance are correlated [20]. VR can affect presence [21]. Furthermore, action., symbolic, sensory and social immersion enhance motivation [21], [22]. Here, cybersickness can also play a role, and if one feels cybersick, the sense of presence is affected [23].

\subsubsection{User Acceptance}

Empirical evidence suggests that positive effects of VR and AR are reported in education [15, 16, 24], smart cities [25], health and medicine [26], and teamwork [27]. Online VR can even build trust [28] and is, therefore, relevant to e-commerce as intentions to transact [29] and purchase [30].

A prominent model of user acceptance is the technology acceptance model (TAM), introduced by Davis [31], while more recent research has introduced the virtual reality hardware acceptance model (VR-HAM) [32]. It has been shown that the TAM also holds true in a WebVR ecommerce setting [33].

Furthermore, researchers explicitly call for more research on MR and mention providing users with userfriendly and effective manuals in the context of assembly as a further opportunity for research [34].

Empirical evidence suggests that VR manuals are easier to comprehend than traditional user manuals and can lower costs [35].

\subsubsection{Usability}

User experience (UX) can cover the dimensions contained in TAM (perceived ease of use and perceived usefulness) but has a more holistic approach covering the experience as a whole. Therefore, hedonic and utilitarian aspects are important, and research extending the TAM links hedonic aspects to perceived usefulness, which, in turn, affects users' intention to use [8].

Usability as a construct and concept of how easy and intuitive an artifact or object can be used by its user is omnipresent in IT artifacts, and the virtual and 
augmented worlds are no exception. Furthermore, empirical findings suggest that VR can positively affect usability [21]. Therefore, in this study, this concept is also present and measured.

\section{Method}

Of the invitations sent to 145 participants to start the online experiment, 96 were completed and can be considered for further analysis.

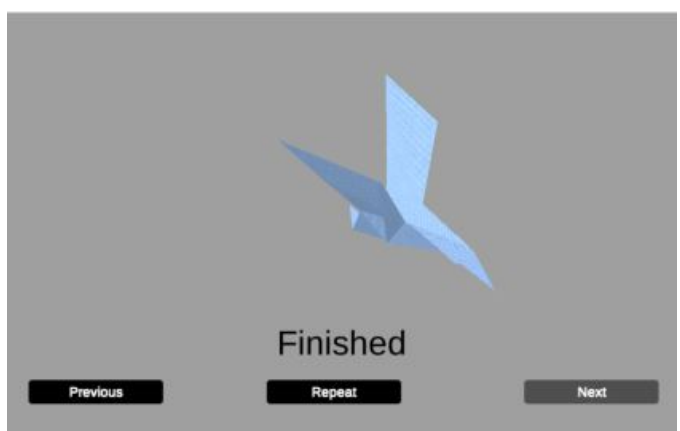

Figure 1: Start screen of the WebVR manual

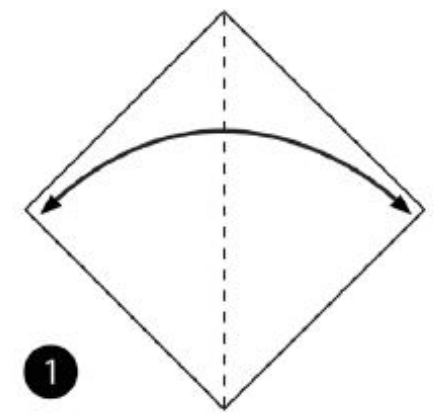

Figure 2: First step of the paper manual

\subsection{Operationalization}

The online questionnaire contains questions regarding the time taken to solve the task, transfer of knowledge, motivation, sense of presence, usability, cognition, imagination, and comprehensibility. These variables are measured with a 5-point Likert scale. The Likert scale items are reversed $(1=$ completely agree to 5 = completely disagree).

Because of the COVID-19 pandemic, this research was not conducted in the lab, but as an online experiment with random allocation of participants to the treatment and the control group.

The task at hand for this online experiment is to fold an origami figure of a flying duck (see Figure 1) [36] using a paper manual for group A (in the online experiment, a PDF file with the steps as well as an illustration of the final product is used; see Figure 2), and for group B, with the help of WebVR, a manual with 3D WebVR representation of the steps as well as the final product (see Figure 1) is used. After finishing the task, the participants are presented with an online questionnaire. They had to report the time it took them to finish the task as well as the quality (number of errors) by self-reported measures.

The items for motivation, sense of presence, comprehensibility, and transfer of knowledge are drawn from Huang et al. [37] and imagination from Huang et al. and Burdera and Coiffet [7]. The scale for usability is drawn from Thomas et al. [38] and cognition from Jansen-Osmann [39].

These scales were used because developing our own items did not seem feasible for this first comparison of WebVR to a traditional user manual and for comparability reasons to prior research. Furthermore, no scales were available in the context of user manuals regarding the constructs mentioned above. Additionally, the authors argue that it is feasible to use scales from prior research as learning and user manuals can be seen as related in a sense that somebody does not understand how to do a specific task and thus consults a user manual to obtain this knowledge or learn how to execute the task at hand.

A pretest of the questionnaire was conducted before sending out the invitation to participate in an online experiment by e-mail.

\subsection{Hypotheses}

Based on the literature and meta-analysis introduced in the literature part of this paper, hypotheses are derived and verified in the experiment and later tested in the data analysis. The derived hypotheses are listed in Table 1. Both VR and AR have shown positive effects on learning $[15,16,24]$; thus, hypotheses 1 and 2 are derived. As the 3D WebVR representation of folding an origami is richer than a PDF user manual, hypothesis 2 is derived. Prior research suggests that AR [24] and VR [21, 37, 4044] technology can have a positive effect on motivation; hence, hypothesis 4 is derived. If the transfer of knowledge with WebVR is easier, this should reduce the time needed to solve the task at hand, which is hypothesis 5. As past research suggests positive effects of sense of presence on learning, hypothesis 6 is derived. Furthermore, the positive effects of usability suggest that it could moderate hypotheses 1 to 4 . Therefore, hypothesis 7 is derived. In prior research, cognition plays a role when processing information in virtual worlds; hence, hypothesis 8 is derived. Closely linked is the line of argument that if one can better imagine, in this case, the steps needed to obtain the final folded origami, this mediates hypothesis 2 and constitutes hypothesis 9. Comprehensibility can arguably affect the transfer of 
knowledge, quality of the end product, and motivation; thus, hypothesis 10 is derived, positing mediating effects on hypotheses 2 to 4 .

Table 1: Overview of the Hypotheses

\begin{tabular}{|c|l|l|}
\hline$\#$ & \multicolumn{1}{|c|}{ Text } & Result \\
\hline 1 & $\begin{array}{l}\text { It takes less time to solve a task } \\
\text { with the WebVR manual than with } \\
\text { the paper manual. }\end{array}$ & Accept \\
\hline 2 & $\begin{array}{l}\text { The transfer of knowledge is eas- } \\
\text { ier with a WebVR manual than } \\
\text { with a paper manual. }\end{array}$ & Accept \\
\hline 3 & $\begin{array}{l}\text { The quality of the end product is } \\
\text { higher with a WebVR manual than } \\
\text { with a paper manual. }\end{array}$ & Reject \\
\hline 4 & $\begin{array}{l}\text { The motivation is higher with } \\
\text { WebVR manuals than with paper } \\
\text { manuals. }\end{array}$ & Accept \\
\hline 5 & $\begin{array}{l}\text { The easier transfer of knowledge } \\
\text { reduces the time with solving the } \\
\text { task at hand. }\end{array}$ & Accept \\
\hline 6 & $\begin{array}{l}\text { The sense of presence moderates } \\
\text { H1 to H4. }\end{array}$ & Reject \\
\hline 7 & Usability moderates H1 to H4. & Accept \\
\hline 8 & $\begin{array}{l}\text { Cognition mediates the effect in } \\
\text { H2. }\end{array}$ & Accept \\
\hline 9 & $\begin{array}{l}\text { Imagination mediates the effect in } \\
\text { H2. }\end{array}$ & Accept \\
\hline 10 & $\begin{array}{l}\text { Comprehensibility mediates the } \\
\text { effect in H2 and H4. }\end{array}$ & $\begin{array}{l}\text { Accept } \\
\text { (partial } \\
\text { media- } \\
\text { tion) }\end{array}$ \\
\hline
\end{tabular}

\section{Results, Discussion, Implications, and Limitations}

Data collection was conducted in the spring term of 2020 , and a total of 96 valid and complete surveys were reported.

\subsection{Sample Description}

The participants in group A (paper manual) have an average age of $29.58(\mathrm{SD}=8.4)$ years, while the participants in group B (virtual manual) have an average age of $27.75(\mathrm{SD}=5.6)$ years. Group A has 11 female and 32 male participants, while group B contains 23 female and 30 male participants. A comparison of distribution regarding gender did not reveal significant results regarding the constructs listed in Table 2. The total number of participants (n) is 96,43 participants in group A and 53 in group B, and 77.1 percent hold a higher education or academic degree.

\subsection{Data Analysis}

IBM SPSS was used for data analysis.

\subsubsection{Reliability}

Before conducting further analysis, construct reliability was assessed by calculating and comparing Cronbach's alpha values to the cutoff value of .7 suggested by Nunally [45] (an overview is given in Table 2).

Table 2: Reliability (Cronbach's Alpha)

\begin{tabular}{|c|c|c|}
\hline Construct & $\begin{array}{c}\text { Cronbach's } \\
\text { Alpha }\end{array}$ & $\begin{array}{c}\# \\
\text { Items }\end{array}$ \\
\hline $\begin{array}{c}\text { Transfer of } \\
\text { Knowledge }\end{array}$ & 0.928 & 3 \\
\hline Motivation & 0.959 & 3 \\
\hline Usability & 0.843 & 3 \\
\hline Sense of Presence & 0.949 & 3 \\
\hline Imagination & 0.955 & 3 \\
\hline Comprehensibility & 0.973 & 3 \\
\hline Cognition & 0.969 & 3 \\
\hline
\end{tabular}

All $\alpha$ values are well above the recommended cutoff value of .7. Therefore, further analysis is conducted.

Table 3: Descriptive Statistics

\begin{tabular}{|c|c|c|c|}
\hline Group & n & Mean & SD \\
\hline \multicolumn{4}{|c|}{ Quality } \\
\hline A & 43 & 2.74 & 1.311 \\
\hline B & 53 & 2.32 & 1.312 \\
\hline \multicolumn{4}{|c|}{ Transfer of Knowledge } \\
\hline A & 43 & 3.7597 & 0.9381 \\
\hline B & 53 & 1.9623 & 0.8182 \\
\hline \multicolumn{4}{|c|}{ Motivation } \\
\hline A & 43 & 3.9922 & 0.8591 \\
\hline B & 53 & 1.7736 & 0.7004 \\
\hline \multicolumn{4}{|c|}{ Usability } \\
\hline A & 43 & 2 \\
\hline B & 53 & 1.8365 & 0.6862 \\
\hline \multicolumn{5}{|c|}{ Sense of Presence } \\
\hline A & 43 & 3.9225 & 0.7916 \\
\hline B & 53 & 1.7107 & 0.7368 \\
\hline \multicolumn{4}{|c|}{ Imagination } \\
\hline A & 43 & 3.8295 & 0.6721 \\
\hline B & 53 & 1.6101 & 0.68 \\
\hline
\end{tabular}




\begin{tabular}{|c|c|c|c|}
\hline Group & n & Mean & SD \\
\hline \multicolumn{4}{|c|}{ Comprehensibility } \\
\hline A & 43 & 3.2868 & 1.1399 \\
\hline B & 53 & 1.5346 & 0.7549 \\
\hline \multicolumn{4}{|c|}{ Cognition } \\
\hline A & 43 & 3.5039 & 0.874 \\
\hline B & 53 & 1.6226 & 0.7192 \\
\hline
\end{tabular}

A comparison of descriptive values such as the mean values in Table 3 shows that lower values in group B are in line with theory as the Likert scale items are reversed ( $1=$ completely agree to $5=$ completely disagree).

Because the values do not follow a normal distribution, a Mann-Whitney U-test is conducted to test for differences between the groups and to test the hypotheses of this study.

\subsubsection{Hypotheses Testing}

In Table 4, an overview of the constructs tested with the Mann-Whitney U-test is given. Apart from quality and usability, all other constructs show significant differences.

Table 4: Mann-Whitney U-Test

\begin{tabular}{|l|c|c|c|c|}
\hline Construct & $\mathbf{U}$ & $\mathbf{S i g}$ & $\mathbf{Z}$ & $\mathbf{r}$ \\
\hline Time taken & 526 & .000 & -4.604 & -0.47 \\
\hline Quality & 917.5 & .091 & -1.692 & -0.173 \\
\hline $\begin{array}{l}\text { Transfer of } \\
\text { knowledge }\end{array}$ & 195 & .000 & -6.995 & -0.714 \\
\hline Motivation & 89.5 & .000 & -7.797 & -0.796 \\
\hline Usability & 907 & .079 & -1.754 & -0.712 \\
\hline $\begin{array}{l}\text { Sense of } \\
\text { Presence }\end{array}$ & 77.5 & .000 & -7.899 & -0.179 \\
\hline $\begin{array}{l}\text { Imagina- } \\
\text { tion }\end{array}$ & 73 & .000 & -7.983 & -0.815 \\
\hline $\begin{array}{l}\text { Compre- } \\
\text { hensibility }\end{array}$ & 262 & .000 & -6.58 & -0.672 \\
\hline Cognition & 121 & .000 & -7.608 & -0.776 \\
\hline
\end{tabular}

Because the time taken significantly differs between the treatment and control group, H1 is accepted. Therefore, it takes less time to solve the task at hand with a WebVR manual than with a paper manual.

Transfer of knowledge does significantly differ; therefore, $\mathrm{H} 2$ is accepted, and a WebVR manual does lead to an easier transfer of knowledge than a paper manual.

Quality does not significantly differ between groups; therefore, $\mathrm{H} 3$ is rejected, and a WebVR manual does not lead to higher quality than a paper manual.

Motivation significantly differs between the groups; therefore, H4 is accepted, and a WebVR manual leads to higher motivation than a paper manual.
Knowledge transfer significantly differs; hence, H5 is accepted, and a WebVR manual leads to higher knowledge transfer and thus a shorter time spent (see H1) for solving the task.

H6 is tested by means of regression, which includes sense of presence and time, knowledge transfer, quality, and motivation. None of the regressions showed a significant interaction term; therefore, $\mathrm{H} 6$ is rejected.

$\mathrm{H} 7$ is tested by means of regression. Time $(\beta=1.659$, $\mathrm{p}=.026)$, transfer of knowledge $(\beta=.680, \mathrm{p}=.002)$, and motivation $(\beta=.505, \mathrm{p}=.016)$ are all significant. The interaction term of the quality $(\beta=.726, p=.046)$ construct is significant as well. Therefore, H7 is accepted, and usability moderates the effects in $\mathrm{H} 1$ to $\mathrm{H} 4$.

H8 is tested by means of regression (see Table 5 for an overview). Path A leads from the independent variable (IV) to the mediator, whereas path $\mathrm{B}$ leads from the mediator to the dependent variable (DV). The direct effect is from the IV to the DV.

\section{Table 5: Mediation Analysis}

\begin{tabular}{|l|c|c|c|c|}
\hline Path & Beta & SD & t & p \\
\hline$A$ & -1.881 & 0.167 & -11.215 & .000 \\
\hline$B$ & 0.846 & 0.096 & 8.776 & .000 \\
\hline$C$ & -1.797 & 0.183 & -9.727 & .000 \\
\hline Direct & -0.205 & 0.260 & -0.791 & .430 \\
\hline
\end{tabular}

Because path $A$ and path $B$ are significant, the direct effect is a mediation that can be reported. Therefore, $\mathrm{H} 8$ is accepted.

The mediation analysis in Table 6 and Table 7 suggests that a mediation effect can be reported here as well, and $\mathrm{H} 9$ is accepted. Therefore, imagination mediates the effects in $\mathrm{H} 2$ and $\mathrm{H} 4$.

Table 6: Mediation Analysis (Imagination/Knowledge Transfer)

\begin{tabular}{|l|c|c|c|c|}
\hline Path & Beta & SD & t & p \\
\hline$A$ & -2.219 & 0.141 & -15.783 & .000 \\
\hline$B$ & 0.787 & 0.139 & 5.653 & .000 \\
\hline$C$ & -1.797 & 0.184 & -9.773 & .000 \\
\hline Direct & -0.051 & 0.383 & -0.132 & .895 \\
\hline
\end{tabular}

Table 7: Mediation Analysis (Imagination/Motivation)

\begin{tabular}{|l|c|c|c|c|}
\hline Path & Beta & SD & t & p \\
\hline$A$ & -2.219 & 0.141 & -15.783 & .000 \\
\hline$B$ & 0.719 & 0.120 & 6.012 & .000 \\
\hline$C$ & -2.219 & 0.164 & -13.501 & .000 \\
\hline Direct & -0.624 & 0.329 & -1.895 & .061 \\
\hline
\end{tabular}


Table 8: Mediation Analysis (Comprehensibility/Motivation)

\begin{tabular}{|l|c|c|c|c|}
\hline Path & Beta & SD & t & p \\
\hline$A$ & -1.752 & 0.205 & -8.561 & .000 \\
\hline$B$ & 0.747 & 0.064 & 11.602 & .000 \\
\hline$C$ & -1.797 & 0.184 & -9.773 & .000 \\
\hline $\begin{array}{l}\text { Di- } \\
\text { rect }\end{array}$ & -0.488 & 0.182 & -2.683 & .009 \\
\hline
\end{tabular}

Table 9: Mediation Analysis (Comprehensibility/Motivation)

\begin{tabular}{|l|c|c|c|c|}
\hline Path & Beta & SD & t & p \\
\hline$A$ & -1.752 & 0.205 & -8.561 & .000 \\
\hline$B$ & 0.550 & 0.060 & 9.170 & .000 \\
\hline$C$ & -2.219 & 0.164 & -13.501 & .000 \\
\hline Direct & -1.255 & 0.184 & -6.811 & .000 \\
\hline
\end{tabular}

The data in Table 8 and Table 9 suggest that mediation is present as both path $\mathrm{A}$ and path $\mathrm{B}$ are significant. However, because in both tables, the direct effect is also significant, a partial mediation must be reported. Therefore, $\mathrm{H} 10$ is accepted as significant mediation is present.

\subsection{Discussion}

The results of this study are interesting as it takes less long to fold an origami duck (task at hand) with WebVR than with a paper manual. Furthermore, motivation, a relevant construct in the context of learning, is higher when interacting with WebVR than with a paper manual. This is in line with prior research on AR [24] and VR [21,37, 40-44] and can now be confirmed for WebVR as well.

The effects of WebVR on time as well as on motivation are moderated by usability. Prior research finds mediating effects of ease of use [31,32], but latest findings on TAM [8] applied to VR find no significant path of ease of use. Hence, further research is needed. Furthermore, mediation is present. Cognition and imagination mediate the effect of knowledge transfer. Furthermore, comprehensibility partially mediates knowledge transfer as well as motivation.

However, the quality of the product isn't higher in WebVR compared with a paper manual.

\subsection{Implications}

The results of this study suggest that WebVR can help in solving tasks that are unknown at first and are of a complex nature. Not only does the time decrease to solve this task, but also motivation is higher in a WebVR setting than in that of a paper manual. Therefore, it is advised to identify and evaluate further use cases such as the one presented in this paper to enhance learning experiences as well as be more cost-efficient (less time) in a business context.

Furthermore, WebVR not only increases the level of motivation but also reduces cognitive load while performing the task because of the interaction (turning of the object and interacting with the manual) and the WebVR visualization, which is better for 3D objects like the origami duck.

\subsection{Limitations}

A student sample must be considered. Furthermore, the quality and time spent to solve the task are self-reported measures, and this must be considered when interpreting the results of this study.

This study was conducted with a task that benefits from 3D representation as the object can be turned and interaction with the object is presumably beneficial regarding the solving of the task.

\section{Further Research}

More complex analysis, for example, SEM (structural equation modeling), could help shed light on the mediating and moderating relationships as well as the direct and indirect effects that some prior studies have found for ease of use [31], [32] and other latest research have not [8].

This study focuses on the folding of an origami duck, and this may not be a typical business case. Hence, further research may evaluate additional use cases with a more business-relevant touch, such as executing maintenance tasks.

\section{Concluding Remarks}

The key takeaway is that WebVR can support users and customers when solving complex tasks. Prior research on AR and VR has shown positive effects of this technology, but with these results, WebVR can be a valid option for implementing user manuals in an interactive and visually more modern way than providing a static PDF. This has positive effects on the time needed to execute the task explained with WebVR.

Academics and practitioners alike are invited to identify further use cases and evaluate in their field if WebVR could enhance learning experiences as well as online service encounters and cut costs by reducing the time needed to solve tasks and learn new skills as well as increasing motivation, a key success factor regarding learning outcomes.

It has to be mentioned that usability moderates some effects reported in this study, and hence, it should be 
taken into consideration when implementing WebVR applications.

WebVR manuals show higher levels of comprehensibility; therefore, they presumably could contribute to enhancing usability.

Because the WebVR technology runs without any additional hardware on many platforms in standard browsers, use cases where paper manuals are present are worth evaluating regarding the potentials of WebVR as the benefits shown in the data presented in this study.

\section{References}

[1] S. Garg, 'Virtual Reality (VR) Market | Size, Share and Market Forecast to 2024 | MarketsandMarkets', Markets and Markets, Nov. 21, 2019. https://www.marketsandmarkets.com/Market-Reports/reality-applications-market-458.html (accessed Mar. 21, 2020).

[2] C. Dibbern, M. Uhr, D. Krupke, and F. Steinicke, 'Can WebVR further the adoption of Virtual Reality?', in Mensch und Computer 2018 Usability Professionals, Bonn, 2018, pp. $377-$ 384.

[3] Economist, 'Headset technology is cheaper and better than ever', The Economist, vol. Technology QUARTERLY, Oct. 01, 2020. Accessed: Nov. 23, 2020. [Online]. Available: https://www.economist.com/technology-quarterly/2020/10/01/headset-technology-is-cheaperand-better-than-ever

[4] C. Flavián, S. Ibáñez-Sánchez, and C. Orús, 'The impact of virtual, augmented and mixed reality technologies on the customer experience', Journal of Business Research, vol. 100, pp. 547560, Jul. 2019, doi:

10.1016/j.jbusres.2018.10.050.

[5] P. Milgram, H. Takemura, a Utsumi, and F. Kishino, 'Mixed Reality ( MR ) Reality-Virtuality ( RV ) Continuum', Systems Research, vol. 2351, no. Telemanipulator and Telepresence Technologies, pp. 282-292, 1994, doi: 10.1.1.83.6861.

[6] R. Dörner, W. Broll, P. F. Grimm, and B. Jung, Eds., Virtual und Augmented Reality (VR/AR): Grundlagen und Methoden der Virtuellen und Augmentierten Realität, 2nd ed. Berlin Heidelberg: Springer Vieweg, 2013.

[7] G. Burdea and P. Coiffet, Virtual reality technol$o g y$, 2nd ed. Hoboken, N.J: J. Wiley-Interscience, 2003.

[8] C. Sagnier, E. Loup-Escande, D. Lourdeaux, I. Thouvenin, and G. Valléry, 'User Acceptance of Virtual Reality: An Extended Technology Acceptance Model', International Journal of Human-Computer Interaction, vol. 36, no. 11, pp.
993-1007, Jul. 2020, doi:

10.1080/10447318.2019.1708612.

[9] V. Andre, 'Bringing Mixed Reality to the Web | The Mozilla Blog', dist://ed, Oct. 20, 2017. https://blog.mozilla.org/en/mozilla/bringingmixed-reality-web/ (accessed Jun. 14, 2021).

[10] 'A-Frame - Make WebVR', A-Frame. https://aframe.io (accessed Jun. 14, 2021).

[11] Z. Lv, T. Yin, Y. Han, Y. Chen, and G. Chen, 'WebVR — Web Virtual Reality Engine Based on P2P network', $J N W$, vol. 6, no. 7, pp. 990998, Jul. 2011, doi: 10.4304/jnw.6.7.990-998.

[12] R. Palmarini, J. A. Erkoyuncu, R. Roy, and H. Torabmostaedi, 'A systematic review of augmented reality applications in maintenance', $R o$ botics and Computer-Integrated Manufacturing, vol. 49, pp. 215-228, Feb. 2018, doi: 10.1016/j.rcim.2017.06.002.

[13] M. Fiorentino, A. E. Uva, M. Gattullo, S. Debernardis, and G. Monno, 'Augmented reality on large screen for interactive maintenance instructions', Computers in Industry, vol. 65, no. 2, pp. 270-278, Feb. 2014, doi: 10.1016/j.compind.2013.11.004.

[14] X. Fan, Z. Chai, N. Deng, and X. Dong, 'Adoption of augmented reality in online retailing and consumers' product attitude: A cognitive perspective', Journal of Retailing and Consumer Services, vol. 53, p. 101986, Mar. 2020, doi: 10.1016/j.jretconser.2019.101986.

[15] I. Reisoğlu, B. Topu, R. Yılmaz, T. Karakuş Yılmaz, and Y. Göktaş, '3D virtual learning environments in education: a meta-review', Asia Pacific Educ. Rev., vol. 18, no. 1, Art. no. 1, Mar. 2017, doi: 10.1007/s12564-016-9467-0.

[16] J. Garzón, J. Pavón, and S. Baldiris, 'Systematic review and meta-analysis of augmented reality in educational settings', Virtual Reality, vol. 23, no. 4, pp. 447-459, Dec. 2019, doi: 10.1007/s10055019-00379-9.

[17] V. Batdi and T. Talan, 'Augmented reality applications: A Meta-analysis and thematic analysis', Turkish Journal of Education, vol. 8, no. 4, Art. no. 4, Oct. 2019, doi: 10.19128/turje.581424.

[18] M. Akçayır and G. Akçayır, 'Advantages and challenges associated with augmented reality for education: A systematic review of the literature', Educational Research Review, vol. 20, pp. 1-11, Feb. 2017, doi: 10.1016/j.edurev.2016.11.002.

[19] E. C. E. Vidal, J. F. Ty, N. R. Caluya, and Ma. M. T. Rodrigo, 'MAGIS: mobile augmented-reality games for instructional support', Interactive Learning Environments, vol. 27, no. 7, pp. 895907, Oct. 2019, doi: 10.1080/10494820.2018.1504305. 
[20] J. H. Bailey and B. G. Witmer, 'Learning and Transfer of Spatial Knowledge in a Virtual Environment', Proceedings of the Human Factors and Ergonomics Society Annual Meeting, vol. 38 , no. 18 , pp. 1158-1162, Oct. 1994, doi: $10.1177 / 154193129403801803$.

[21] G. Makransky and L. Lilleholt, 'A structural equation modeling investigation of the emotional value of immersive virtual reality in education', Education Tech Research Dev, vol. 66, no. 5, pp. 1141-1164, Oct. 2018, doi: 10.1007/s11423018-9581-2.

[22] C. J. Dede, J. Jacobson, and J. Richards, 'Introduction: Virtual, Augmented, and Mixed Realities in Education', in Virtual, Augmented, and Mixed Realities in Education, D. Liu, C. Dede, R. Huang, and J. Richards, Eds. Singapore: Springer Singapore, 2017, pp. 1-16. doi: 10.1007/978-981-10-5490-7_1.

[23] B. G. Witmer and M. J. Singer, 'Measuring Presence in Virtual Environments: A Presence Questionnaire', Presence: Teleoperators and Virtual Environments, vol. 7, no. 3, pp. 225-240, Jun. 1998, doi: 10.1162/105474698565686.

[24] I. Radu, 'Augmented reality in education: a meta-review and cross-media analysis', Personal and Ubiquitous Computing, vol. 18, no. 6, pp. 1533-1543, Aug. 2014, doi: 10.1007/s00779013-0747-y.

[25] Z. Lv, T. Yin, X. Zhang, H. Song, and G. Chen, 'Virtual Reality Smart City Based on WebVRGIS', IEEE Internet of Things Journal, vol. 3, no. 6, pp. 1015-1024, Dec. 2016, doi: 10.1109/JIOT.2016.2546307.

[26] E. Z. Barsom, M. Graafland, and M. P. Schijven, 'Systematic review on the effectiveness of augmented reality applications in medical training', Surgical Endoscopy, vol. 30, no. 10, pp. 41744183, Oct. 2016, doi: 10.1007/s00464-016-48006.

[27] F. Salvetti, B. Bertagni, P. Ingrassia, and G. Pratticò, 'HoloLens, Augmented Reality and Teamwork: Merging Virtual and Real Workplaces', International Journal of Advanced Corporate Learning, vol. 11, no. 1, pp. 44-47, Feb. 2018, doi: 10.3991/ijac.v11i1.9228.

[28] P. Papadopoulou, 'Applying virtual reality for trust-building e-commerce environments', Virtual Reality, vol. 11, no. 2-3, pp. 107-127, Jun. 2007, doi: 10.1007/s10055-006-0059-x.

[29] H. D. McKnight, V. Choudhury, and C. Kacmar, 'The impact of initial consumer trust on intentions to transact with a web site: a trust building model', The Journal of Strategic Information
Systems, vol. 11, no. 3, pp. 297-323, Dec. 2002, doi: 10.1016/S0963-8687(02)00020-3.

[30] L. H. S. Samuel, M. S. Balaji, and K. K. Wei, 'An Investigation of Online Shopping Experience on Trust and Behavioral Intentions', Journal of Internet Commerce, vol. 14, no. 2, pp. 233-254, Apr. 2015, doi: 10.1080/15332861.2015.1028250.

[31] F. D. Davis, 'A technology acceptance model for empirically testing new end-user information systems: Theory and results', PhD Thesis, MIT, 1986.

[32] K. T. Manis and D. Choi, 'The virtual reality hardware acceptance model (VR-HAM): Extending and individuating the technology acceptance model (TAM) for virtual reality hardware', Journal of Business Research, vol. 100, pp. 503-513, Jul. 2019, doi: 10.1016/j.jbusres.2018.10.021.

[33] R. Seiler and T. Keller, 'WebVR vs. pictures of products in e-commerce: effects on trust, perceived ease of use, perceived usefulness, and intention to use', in ES 2021: 19th International Conference e-Society 2021, Virtual, 3-5 March 2021, 2021, pp. 193-200.

[34] J. Zauner, M. Haller, A. Brandl, and W. Hartman, 'Authoring of a mixed reality assembly instructor for hierarchical structures', in The Second IEEE and ACM International Symposium on Mixed and Augmented Reality, 2003. Proceedings., Oct. 2003, pp. 237-246. doi: 10.1109/ISMAR.2003.1240707.

[35] R. Adelmann, 'Augmented Reality in der industriellen Praxis', in Virtual Reality und Augmented Reality in der Digitalen Produktion, H. Orsolits and M. Lackner, Eds. Wiesbaden: Springer Fachmedien, 2020, pp. 7-32. doi: 10.1007/978-3-65829009-2 2.

[36] 'How To Make An Easy Origami Flying Duck', Origami Instructions | Origami Tutorial, Jan. 31, 2021. https://www.origami-tutorial.com/origamiflying-duck.html (accessed Jun. 15, 2021).

[37] H.-M. Huang, U. Rauch, and S.-S. Liaw, 'Investigating learners' attitudes toward virtual reality learning environments: Based on a constructivist approach', Computers \& Education, vol. 55, no. 3, Art. no. 3, Nov. 2010, doi: 10.1016/j.compedu.2010.05.014.

[38] O. Thomas, D. Metzger, and H. Niegemann, Eds., Digitalisierung in der Aus- und Weiterbildung: Virtual und Augmented Reality für Industrie 4.0. Gabler Verlag, 2018. doi: 10.1007/978-3662-56551-3.

[39] P. Jansen-Osmann, 'Kognition von Distanzen: laborexperimentelle Untersuchungen in virtuellen Umgebungen', Duisburg-Essen, Duisburg-Essen, 
1998. Accessed: Jun. 15, 2021. [Online]. Available: https://duepublico2.uni-due.de-

receive/duepublico mods 00005066

[40] D. Vergara, M. P. Rubio, and M. Lorenzo, 'New Approach for the Teaching of Concrete Compression Tests in Large Groups of Engineering Students', Journal of Professional Issues in Engineering Education and Practice, vol. 143, no. 2, p. 05016009, Apr. 2017, doi: 10.1061/(ASCE)EI.1943-5541.0000311.

[41] P. Wang, P. Wu, J. Wang, H.-L. Chi, and X. Wang, 'A Critical Review of the Use of Virtual Reality in Construction Engineering Education and Training', International Journal of Environmental Research and Public Health, vol. 15, no. 6, Art. no. 6, Jun. 2018, doi: 10.3390/ijerph15061204.

[42] B. Chavez and S. Bayona, 'Virtual Reality in the Learning Process', in Trends and Advances in Information Systems and Technologies, Cham, 2018, pp. 1345-1356. doi: 10.1007/978-3-319$77712-2129$.

[43] J. Radianti, T. A. Majchrzak, J. Fromm, and I. Wohlgenannt, 'A systematic review of immersive virtual reality applications for higher education: Design elements, lessons learned, and research agenda', Computers \& Education, vol. 147, p. 103778, Apr. 2020, doi: 10.1016/j.compedu.2019.103778.

[44] Z. Merchant, E. T. Goetz, L. Cifuentes, W. Keeney-Kennicutt, and T. J. Davis, 'Effectiveness of virtual reality-based instruction on students' learning outcomes in K-12 and higher education: A meta-analysis', Computers \& Education, vol. 70, pp. 29-40, 2014, doi: https://doi.org/10.1016/j.compedu.2013.07.033.

[45] J. Nunally, Psychometric theory. New York: McGraw-Hill, 1978. 